\title{
Behavior and neuropsychiatric changes in experimental chronic toxoplasmosis: Histopathological and immunohistochemical studies
}

Original

Article

\author{
Samia E Etewa ${ }^{1}$, Mohamed H Sarhan ${ }^{1}$, Howayda SF Moawad $^{1}$, Samira M \\ Mohammad $^{1}$, Mohamed A Samir ${ }^{2}$, Ahmad M Kandil ${ }^{3}$, Eman M Mostafa ${ }^{1}$ \\ Departments of Medical Parasitology ${ }^{1}$ and Zoonoses ${ }^{2}$, Faculties of Medicine and \\ Veterinary Medicine, Zagazig University, Zagazig, and Pathology ${ }^{3}$, Faculty of Medicine, Al- \\ Azhar University, Cairo, Egypt
}

\section{ABSTRACT}

Background: T. gondii is an intracellular protozoan parasite that can establish a latent infection in the central nervous system that may develop into chronic inflammation resulting in neurobehavioral problems in the host. The processes behind these alterations are still largely mysterious.

Objective: Detection of behavioral, histopathological and immunohistochemical changes in mice infected by T. gondii Me49 strain.

Material and Methods: A total of 105 adult male Swiss albino mice were divided into 60 used for experimental infection, and 45 as control. Assessment of physical appearance was monitored for acute toxoplasmosis daily for three weeks post infection (PI). Correlation between behavior changes and the degree of infection was conducted by measuring histopathological (H\&E and silver stain) and immunohistochemical (presence or absence of CD3, CD138 and caspase-3 immunoreactive cells) parameters weekly starting from $7^{\text {th }}$ week to the $12^{\text {th }}$ week PI.

Results: Infected mice had neurobehavioral problems. Variable degrees of perivascular and interstitial inflammatory infiltrates, astrocytosis, deteriorated neurons, and meningitis were demonstrated by histopathology when compared to uninfected controls. Inflammatory cells (mainly lymphocytes) entered the parenchyma at mild, moderate, and severe levels in the brains of infected mice. Immunohistochemical assessment of CD3, CD138 and caspase-3 revealed a substantial increase in CD3 expression by clusters of activated astrocytes in the cerebral parenchyma, suggesting an increase in astrocyte numbers and function that was progressive over time. CD138 and caspase-3 immunoreactivity showed decreased expression by the activated astrocytes.

Conclusion: Chronic toxoplasmosis causes deterioration in cognitive and emotional behavior of the infected host, resulting in neuropsychiatric and behavioral disturbances.

Keywords: behavior changes, caspase-3, CD3, CD138, immunohistochemistry, T. gondii.

Received: 5 May, 2021, Accepted: 12 August, 2021.

Corresponding Author: Eman M Mostafa, Tel.: +20 1152664614, E-mail: emanmostafa81@gmail.com

Print ISSN: 1687-7942, Online ISSN: 2090-2646, Vol. 14, No. 2, August, 2021.

\section{INTRODUCTION}

Toxoplasma gondii is a parasitic intracellular protozoan that causes toxoplasmosis, a potentially fatal illness in immunocompromised or congenitally affected humans ${ }^{[1]}$. About one-third of the world's population are reportedly infected ${ }^{[2]}$. Congenital toxoplasmosis is estimated to impact 190,000 individuals worldwide per year, resulting in a significant global burden of disease of 1.20 million disability-adjusted life years ${ }^{[3]}$. The ingestion of undercooked and raw meat containing bradyzoite cysts has been linked to human infections. Another critical mode of acquired transmission is food and water polluted with sporulated oocysts containing sporozoites $^{[4]}$. Infection is usually asymptomatic, although in situations of immunodeficiency, significant clinical consequences are common ${ }^{[5]}$.
These single-celled opportunistic parasites can develop a latent infection by differentiating into encysted bradyzoite forms, that may persist in immunocompetent individuals for the rest of their lives without eliciting any signs of infection ${ }^{[6]}$. At any time the cysts may induce development of a chronic clinically asymptomatic infection ${ }^{[7]}$, and can exist for years in the host tissues without generating any local inflammation ${ }^{[8]}$. However, if the equilibrium between the host immune response and parasite immune escape is disrupted, reactivation of parasite growth is associated with symptoms related to the organ affected $^{[9]}$. T. gondii causes various modifications in host neurons and alters certain neuronal signaling mechanisms in chronic infections ${ }^{[10]}$. Furthermore, parasites inside neurons may cause direct neuronal death and atrophy of neuronal functions, while 
inflammation caused by the formation of nitric oxide (NO) and inflammatory cytokines by microglia or immune cells can cause death of adjacent neurons ${ }^{[11]}$. The existence of Toxoplasma cysts in the brain of rat intermediate host is thought to affect physiological functions, resulting in behavioral modifications that influence parasite dissemination to the definite host (Felidae ${ }^{[12]}$. Infected rats were proved to have less fear of unfamiliar scents, sounds, or images, produced by a predator. Behavioral modifications have been linked to increased predation in rats and mice ${ }^{[13]}$. Cat urine and body odors elicit intense innate defense responses in rodents ${ }^{[14]}$. The natural sensitivity of Toxoplasma infected rats to cat urine is diverted, and the odor becomes an attractive feature. Behavior changes in these animals also include stress and acquired fear ${ }^{[15]}$. Lately research suggested that chronic toxoplasmosis causes a variety of host behavior changes in both humans and mice ${ }^{[16]}$, and can also raise the risk of neurological disease ${ }^{[17]}$. T. gondii has been linked to neuropsychiatric conditions ${ }^{[18]}$ as well as mental health issues like depression and self-directed abuse ${ }^{[19]}$. It was noted that during a chronic illness, motor control becomes impaired ${ }^{[16]}$.

Chronic toxoplasmosis is commonly associated with schizophrenia and dementia ${ }^{[13]}$, and based on a metaanalysis review, increased $T$. gondii seropositivity associated-schizophrenia was observed ${ }^{[20]}$. Besides, Alzheimer's and Huntington's diseases, as well as mental health issues such as depression and self-directed abuse were associated with chronic toxoplasmosis ${ }^{[19]}$. However, the processes by which Toxoplasma infection causes such modifications are still unknown. Nonetheless, recent research suggests that the presence of neuropsychiatric disorders in the host is caused by a combination of parasite activity affecting synaptic function and the influence of peripheral host immune activation on the central nervous system $(\mathrm{CNS})^{[16]}$.

On the other hand, CD3 is a multimeric protein complex that is made up of four distinct polypeptide chains: epsilon $(\varepsilon)$, gamma $(\gamma)$, delta $(\delta)$ and zeta $(\zeta)$. It was formerly known as the T3 complex. The CD3 complex is a $\mathrm{T}$ cell co-receptor that interacts with the $\mathrm{T}$ cell receptor in a noncovalent manner ${ }^{[21]}$. In all patient types, increased CD3 densities were observed in the hippocampus/parahippocampus, thalamus/hypothalamus, and frontotemporal cortex, with psychotic and suicidal patients being the most affected $^{[22]}$. Additionally, CD138 (also known as syndecan-1) is primarily expressed on plasma cells, endothelial cells, and epithelial cells' surfaces ${ }^{[23]}$. Interestingly, Kaminski et al. ${ }^{[2]}$ explained $\mathrm{B}$ cell phenotyping, stating that expression of the adhesion molecule CD138 on CD38 high B cells versus CD38 in $B$ cells indicates that at least certain plasmablasts may be plasma cell precursors ${ }^{[25]}$. This molecule is found in almost all antigen-secreting cells in the bone marrow ${ }^{[26]}$.
It is a key component of endothelial cell glycocalyx and is thought to play a role in the negative regulation of inflammatory processes. In rats, glycocalyx depletion resulted in blood brain barrier (BBB) dysfunction and brain edema ${ }^{[27]}$.

Caspases are a class of cysteinyl aspartate-specific proteases that act as core regulators of apoptosis and are strongly conserved in multicellular organisms. In neuronal cells, caspase-3, a member of this family, has been identified as a central mediator of apoptosis ${ }^{[28]}$ T. gondii has a dual effect on cell apoptosis, causing apoptosis in uninfected cells while also preventing apoptosis in infected host cells by direct parasitic interaction with host-cell signaling pathways ${ }^{[29]}$. Non apoptotic neuronal roles, such as synaptic plasticity, dendrite pruning, and learning and memory processes, are mediated by caspase- 3 activation ${ }^{[30]}$.

The aim of this research is to fill in some of the gaps in the literature and potentially clarify the role of chronic toxoplasmosis as co-factor in several psychiatric, neurological, and other neurodegenerative illnesses. Hence, we attempted to detect behavioral changes in mice infected with chronic strain of T. gondii ME-49 using behavioral tests, histopathology, and immunohistochemistry studies in order to characterize the inflammatory response of the host brain tissue to T. gondii.

\section{MATERIAL AND METHODS}

This experimental case control study was conducted during the period from October 2020 to March 2021 in the Medical Parasitology Department, Faculty of Medicine, Zagazig University.

Study design: Sixty adult male Swiss albino mice were used for experimental infection, and another 45 male mice were allocated to the control group. Assessment of physical appearance and autonomic characteristics was monitored for acute toxoplasmosis daily for three weeks PI. Every week starting from $7^{\text {th }}$ week PI (chronic toxoplasmosis) to the $12^{\text {th }}$ week PI (end of the experiment), a correlation was conducted between behavior changes and the degree of infection as measured by histopathological and immunohistochemical parameters. During the last 6 weeks, 14 mice (7 infected and 7 controls) were randomly selected and sacrificed every week from the survived mice (i.e., a total of 42 mice from each group). The remaining survived mice were allocated for strain maintenance. Each brain was excised and divided into two parts. The first part was inspected for the existence and estimation of cyst burden in brain homogenates, while the second part was kept for brain lesions grading in histopathological sections and immunohistochemical studies (presence or absence of CD3, CD138 and caspase-3 immunoreactive cells). 
Parasite strain: Me49 Toxoplasma strain was generously obtained from the Medical Parasitology Department, Faculty of Medicine, Alexandria University. Using a 22-gauge blunt feeding needle and a quantity of brain homogenate calibrated to produce 10 tissue cysts, the strain was maintained by oral passage in outbred Swiss albino mice ${ }^{[31]}$.

Experimental animals: One hundred and five male (7-8 weeks old) Swiss strain of albino mice were obtained from the animal house of Faculty of Medicine, Zagazig University. Male mice were used to avoid problems associated with pregnancy and giving birth and cannibalism. Sixty mice were orally infected with the Me49 type II cystogenic Toxoplasma strain. Oral ingestion of tissue cysts constitutes the most naturalistic route of infection ${ }^{[32]}$. The remaining forty-five mice were used as negative control. Mice were kept in wellventilated cages ( 5 mice/cage), served pellet food with free access to water and maintained under controlled conditions of lighting (12 h light/12 h dark cycle) and temperature $\left(25 \pm 2^{\circ} \mathrm{C}\right)$. Mice were anaesthetized using isoflurane, the animal inhalation anesthetic agent of choice, before any painful procedures.

\section{Physical appearance and autonomic} characteristics $^{[11,33]}$ : All mice were monitored daily for 3 weeks PI, and signs of toxoplasmosis through acute (first 3 weeks) and chronic (after the $7^{\text {th }}$ week) phases were scored.

- Illness behavior: Score zero for active; score one for hunched posture, and score two for delay in movement.

- Palpebral closure: Palpebral closure is considered a sign of pain and an indicator of autonomic instability. This was classified as normal (eyes wide open) = zero, or as abnormal (closed eye) $=$ one.

- Lacrimation: This was graded as absent = zero, or present $=$ one

- Salivation: This was classified as normal = zero, or abnormal = one.

- Tail wounds: This was recorded as absent = zero, or present $=$ one.

- Spatial locomotion: This was evaluated as active = zero, or none $/$ slow = one.

- Stereotyped behavior: Repetitive invariant movements without apparent goal were stereotyped as a form of abnormal behavior. This was graded as lack of stereotyped behavior = zero, and presence of any stereotyped behavior $=$ one.

Behavioral assessments: Experiments were videotaped and interpreted using observer tools (Smart, Germany). Mice were assessed using a series of well-established nominal variables to categorize a variety of health and behavioral traits, as well as motor/ neural function indices after thirty-minutes duration of habituation $^{[34]}$

- Exploratory behavior: This was measured using open field test (OFT) to assess exploratory exercise and locomotor movement ${ }^{[35]}$. Briefly, a $50 \times 50 \times 50 \mathrm{~cm}$ box with a floor divided into middle $(30 \times 30 \mathrm{~cm})$ and peripheral sections was used. Each mouse was placed gently in the center of the field, facing a particular box corner, and scored after being videotaped for $5 \mathrm{~min}$ The average distance travelled, and time spent in the center region were calculated.

- Learning and memory: The Morris water maze (MWM) test was used to assess spatial memory. Swim of mice was tracked, digitalized, and saved for later behavioral analysis using Watermaze apps. Each day, the time spent to find the platform (escape latency) was registered. On the fifth day, the memory index was evaluated using a 60 -sec probe trial without the platform. The number of platform crossings and the average time spent in the quadrant of the former platform location were reported ${ }^{[17]}$.

- Anxiety-like behavior: The tail suspension test (TST) was used to assess the mice's depression and anxiety using the procedure previously mentioned ${ }^{[36]}$ This was interpreted by calculating the immobility period in mice.

T. gondii brain cysts count: Brains of infected mice were harvested and triturated in $1 \mathrm{ml}$ buffered saline (pH 7.2) in a Teflon homogenizer. The total number of cysts in $10 \mu \mathrm{l}$ of homogenate (unstained) was quantified in a hemocytometer at 400-fold magnification. The mean of five different fields was calculated for each mouse $^{[37]}$ as follows: brain cyst burden $=$ number of brain cysts in $10 \mu \mathrm{l}$ homogenate $\mathrm{x} 100 \times 2$.

Histopathological examination of brain cysts (H\&E and silver stain): Specimens from brains were fixed in formalin (10\%), processed for sectioning, and stained by H\&E stain according to Bancroft and Gamble ${ }^{[38]}$ and silver stain (Gordon and Sweet method for reticulin) ${ }^{[39]}$, Histological and metric studies of the brain tissue were performed for monitoring the number and size of brain cysts. Examination was conducted using light Olympus binuclear microscope provided with an integrated calibrated ocular micrometer. A semi-quantitative scoring system consisting of five grades was used ${ }^{[15]}$. While grade 0 indicated no lesion, grade I was a single minimal lesion limited to localized perivascular cuffing with slight mononuclear cell infiltration in the meninges. Grade II identified widespread minimal lesions or a mild lesion including perivascular cuffing, meningitis and local glial cell infiltration. Grade III identified a single moderate lesion including perivascular cuffing, meningitis and focal necrosis with occasional macrophage infiltration. Grade IV indicated widespread moderate lesions or a single severe lesion including perivascular cuffing, meningitis and focal extensive necrosis. The median of the grades of lesions for each mouse was calculated. All sections were analyzed in a blind manner.

Immunohistochemical studies for assessment of CD3, CD138 and caspase-3: Paraffin was dissolved 
and antigen demasking was accomplished by boiling the sections in $10 \mathrm{mM}$ citrate buffer, $\mathrm{pH} 6.0$ (Lab Vision) for 4 min. After blocking endogenous peroxidase function with $15 \% \mathrm{H}_{2} \mathrm{O}_{2}$ for $10 \mathrm{~min}$, nonspecific binding sites were treated with $10 \%$ natural goat serum for $60 \mathrm{~min}$ followed by repeated PBS washings. The used primary antibodies (DAKO, Glostrup, Denmark) were polyclonal rabbit anti-human CD3, monoclonal mouse anti-human CD138, and rabbit polyclonal antibody to caspase-3 (all diluted 1:100), supplemented by secondary antibodies, horseradish peroxidase linked antibodies against mouse or rabbit immunoglobulin (each diluted 1:2000) ${ }^{[40]}$. Semi-quantitative assessment of immunoreactive cells from each brain, i.e., three neighboring sections at the level of the anterior hippocampus were stained for CD3, CD138 and caspase-3, as markers for T-, B-cells and normal tissue structure, respectively. These brain sections were inspected with a light microscope (Olympus, Hamburg, Germany) using a grading scale: $0=$ no cells, $1=$ few cells (low densities), $2=$ many cells (high densities) ${ }^{[38]}$.

Data analysis: Data were statistically analyzed using GraphPad Prism (9.1.0) (Prism, San Diego, CA, USA). Parametric quantitative data were expressed and tested by ANOVA tests. Non-parametric quantitative data were analyzed using Kruskal-Wallis tests. Correlations between variables were tested by the Pearson's $r$ correlation. Statistical significance was set at $P$ values less than 0.05 .
Ethical consideration: The research was carried out in accordance with the rules of Zagazig University's Ethics Committee, based on international animal care regulations.

\section{RESULTS}

Mice death during the experimental study: We started our experiment with 60 infected mice, and 45 mice as negative control. By the end of the experiment, 16 infected mice, and 3 control mice had died, while 44 and 42 mice, respectively survived till scarification.

Assessment during the $1^{\text {st }}$ three weeks (signs of acute phase): Monitoring of infected mice showed decline in neurological and behavioral activity. Abnormalities were noted in infected mice with percentages of $95.2 \%, 92.9 \%, 90.5 \%, 97.6 \%, 88.1 \%$, $95.2 \%$, and $100 \%$ regarding illness behavior, palpebral closure, lacrimation, salivation, tail wounds, spatial locomotion, and stereotyped behavior, respectively in comparison with non-infected mice (Table 1). Control mice showed abnormality in the same parameter of physical appearance with percentages of $0 \%, 2.4 \%, 0 \%$, $4.8 \%, 0 \%, 2.4 \%, 0 \%$, respectively.

Assessment during $7^{\text {th }}$ week to $12^{\text {th }}$ week (signs of chronic phase): Mice with chronic toxoplasmosis underwent a series of behavioral tests, including OFT for

Table 1. Physical appearance and autonomic characteristics findings in all mice.

\begin{tabular}{lccc|ccc}
\hline \hline & \multicolumn{6}{c}{ All mice (84 surviving mice) } \\
\cline { 2 - 7 } & \multicolumn{2}{c}{ Chronically-infected (42) } & \multicolumn{3}{c}{ Control (42) } \\
\cline { 2 - 7 } & Normal & Abnormal & \% & Normal & Abnormal & \% \\
\hline Illness behavior & 2 & 40 & 95.2 & 42 & 0 & 0.0 \\
Palpebral closure & 3 & 39 & 92.9 & 41 & 1 & 2.4 \\
Lacrimation & 4 & 38 & 90.5 & 42 & 0 & 4.0 \\
Salivation & 1 & 41 & 97.6 & 40 & 2 & 0.0 \\
Tail wounds & 5 & 37 & 88.1 & 42 & 0 & 2.4 \\
Spatial locomotion & 2 & 40 & 95.2 & 41 & 1 & 0.0 \\
Stereotyped behavior & 0 & 42 & 100.0 & 42 & 0 & \\
\hline \hline
\end{tabular}

exploration behavior, MWM for learning and memory, and TST for anxiety-like behavior. Toxoplasmosis inhibited mice's spatial exploration and locomotor behaviors. By OFT, the average distance travelled by infected mice $(69.2 \pm 23.8 \mathrm{~cm})$ was significantly $(P<0.001)$ less than that of control mice $(133.6 \pm 26.8$ $\mathrm{cm}$ ) (Fig. 1A). Infected mice, on the other hand, spent more time in the central region $(17.6 \pm 8.0 \mathrm{sec})$ than control mice $(9.0 \pm 3.2 \mathrm{sec})$ (Fig. $1 \mathrm{~B})$, with $P<0.05$. Regarding the former platform crossings, the control group crossed over the platform site more often than affected groups in MWM test (Fig. $1 C, P<0.05$ ). In the spatial probe experiment, infected mice spent less time in the target quadrant $(7.29 \pm 1.96 \mathrm{sec}, P<0.05)$ than control mice (16.44 $\pm .89 \mathrm{sec})$ (Fig. 1D). Furthermore, in TST, the immobility period in infected mice was significantly $(P=0.0036)$ longer than in control mice (32.6 $\pm 1.5 \mathrm{sec}$ versus $16.0 \pm 2.3 \mathrm{sec}$ ) (Fig. 1E).

Assessment of the degree of the infection: The correlations between brain cyst count and brain lesion grading is deduced from tables ( 2 and 3 ). As expected, brain cyst counts and brain lesion grading paralleled each other. Thus, the gradual increase in brain cyst counting with progress of infection was associated with a gradual significant increase in the group median lesion grade; correlation between weeks and brain cyst and median lesion grade were significant $(P=0.02$ and 0.002, respectively) (Fig. 2).

Histopathologic studies: Results revealed variable degrees of perivascular and interstitial inflammatory 

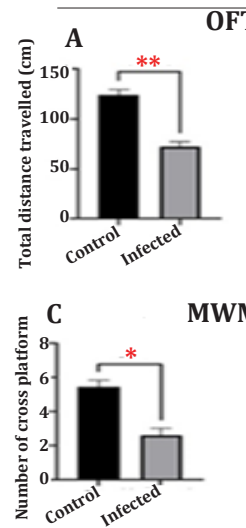
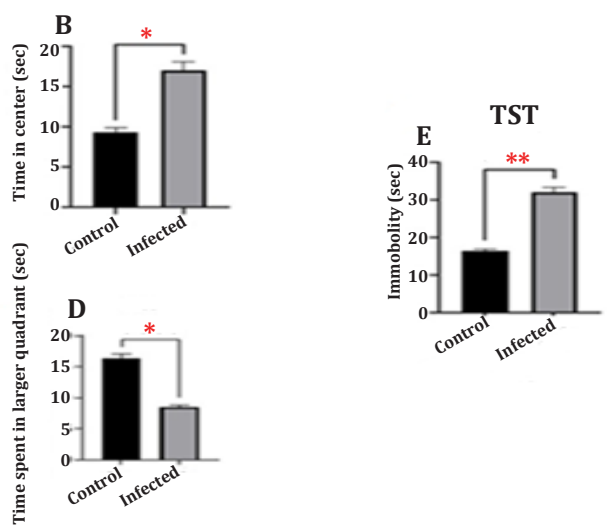

Fig. 1. Behavioral changes in mice with chronic toxoplasmosis. Locomotor activity as measured by (A) total distance travelled (cm), and (B) time spent (sec) in the center by the open field test (OFT). Spatial working memory as measured by (C) number of cross platform and (D) time spent (sec) in target platform in Morris water maze test (MWM). (E) Anxiety-like behavior of mice as measured by time spent in larger quadrant (sec) in tail suspension test (TST).

*: Significant $(P<0.05)$; **: Significant $(P<0.001)$.

Table 2. Mean Toxoplasma brain cyst count in chronically infected mice on $7^{\text {th }}-12^{\text {th }}$ weeks.

\begin{tabular}{|c|c|c|c|c|}
\hline \multirow{2}{*}{ Week } & \multicolumn{3}{|c|}{ Toxoplasma brain cysts in mice } & \multirow{2}{*}{$\begin{array}{c}\text { Statistical } \\
\text { analysis }\end{array}$} \\
\hline & No. of cysts/mice & $\%$ & Mean \pm SD $^{*}$ & \\
\hline $7^{\text {th }}$ & $5 / 7$ & 71.4 & $403.01 \pm 52.44$ & \\
\hline $8^{\text {th }}$ & $5 / 7$ & 71.4 & $451.67 \pm 45.86$ & One way ANOVA test \\
\hline $9^{\text {th }}$ & $6 / 7$ & 85.7 & $471.33 \pm 51.67$ & $F$-ratio = 2.78641 \\
\hline $10^{\text {th }}$ & $7 / 7$ & 100 & $492.01 \pm 52.63$ & $P=0.077$ \\
\hline $11^{\text {th }}$ & $7 / 7$ & 100 & $502.33 \pm 52.70$ & Not significant \\
\hline $12^{\text {th }}$ & $7 / 7$ & 100 & $521.67 \pm 53.66$ & \\
\hline
\end{tabular}

*: Mean number of cysts/ml brain homogenate.

Table 3. Grading and significance of brain lesions in chronically infected mice on $7^{\text {th }}-12^{\text {th }}$ weeks.

\begin{tabular}{|c|c|c|c|c|c|}
\hline Week & Grade & No, & Median & IQR & Statistical analysis \\
\hline $7^{\text {th }}$ & $\begin{array}{c}0 \\
\text { I } \\
\text { II } \\
\text { III } \\
\text { IV }\end{array}$ & $\begin{array}{l}2 \\
2 \\
3 \\
0 \\
0\end{array}$ & I & $1.0-2.0$ & \\
\hline $8^{\text {th }}$ & $\begin{array}{c}0 \\
\text { I } \\
\text { II } \\
\text { III } \\
\text { IV }\end{array}$ & $\begin{array}{l}0 \\
2 \\
3 \\
2 \\
0\end{array}$ & I & $1.0-2.0$ & \\
\hline $9^{\text {th }}$ & $\begin{array}{c}0 \\
\text { I } \\
\text { II } \\
\text { III } \\
\text { IV }\end{array}$ & $\begin{array}{l}0 \\
1 \\
3 \\
2 \\
1\end{array}$ & II & $1.0-3.0$ & $\begin{array}{c}\text { Kruskal Wallis test } \\
H=14.5526\end{array}$ \\
\hline $10^{\text {th }}$ & $\begin{array}{c}0 \\
\text { I } \\
\text { II } \\
\text { III } \\
\text { IV }\end{array}$ & $\begin{array}{l}0 \\
0 \\
2 \\
3 \\
2\end{array}$ & II & $1.0-3.0$ & $\begin{array}{l}P=0.0007 \\
\text { Significant }\end{array}$ \\
\hline $11^{\text {th }}$ & $\begin{array}{c}0 \\
\text { I } \\
\text { II } \\
\text { III } \\
\text { IV }\end{array}$ & $\begin{array}{l}0 \\
0 \\
2 \\
2 \\
3\end{array}$ & II & $1.0-3.0$ & \\
\hline $12^{\text {th }}$ & $\begin{array}{c}0 \\
\text { I } \\
\text { II } \\
\text { III } \\
\text { IV }\end{array}$ & $\begin{array}{l}0 \\
0 \\
1 \\
3 \\
3\end{array}$ & III & $2.0-4.0$ & \\
\hline
\end{tabular}

No.: Number of infected mice in each grade, IQR: Interquartile range.

infiltrates, astrocytosis, degenerated neurons and meningitis. These findings included appearance of microglia (Fig. 3A). Pathological findings included rare encysted bradyzoites (Fig. 3B). Mild, moderate, and intense parenchymal infiltrates of inflammatory cells; mainly lymphocytes were observed (Fig. 3 C-F).
Compared to the normal brain tissue (Fig. 4A), the characteristic tissue cyst was generally round, with a capsule demonstrable by silver impregnation and a diameter which varied between 50 and $120 \mu \mathrm{m}$. The cyst wall stained black with silver stain, and the cyst was never divided by septa (Fig. 4 B, and C). 


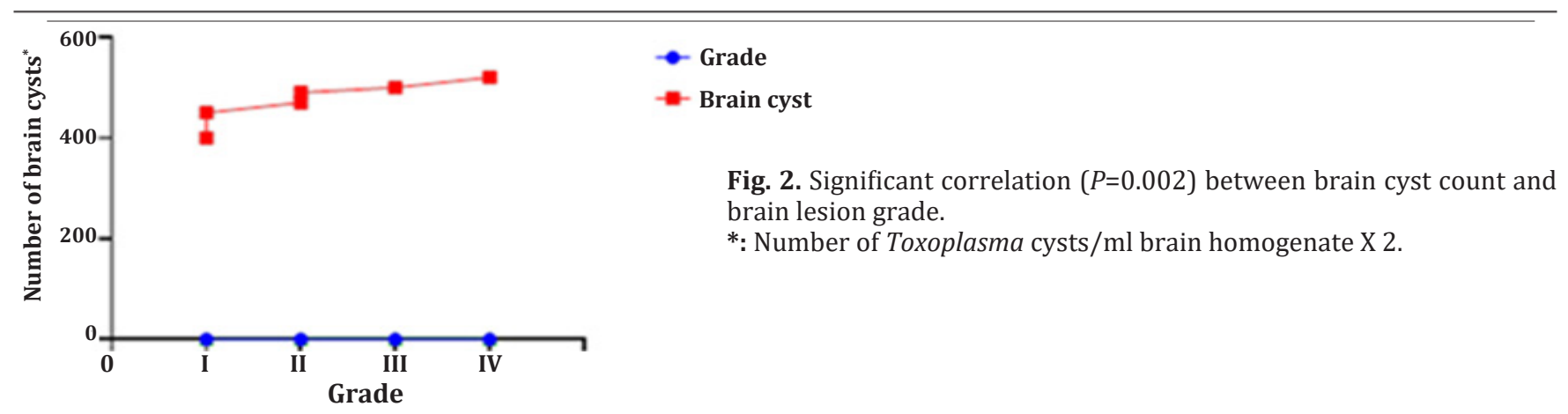

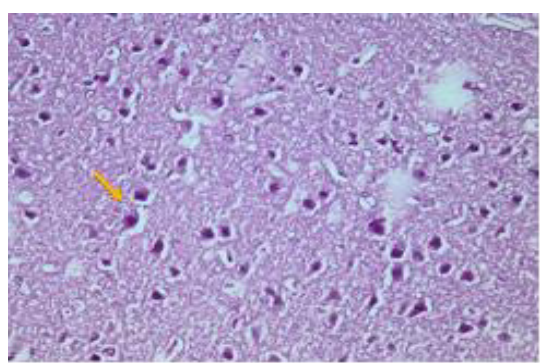

(A)

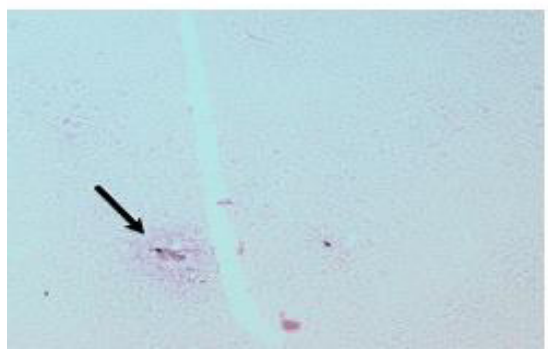

(D)

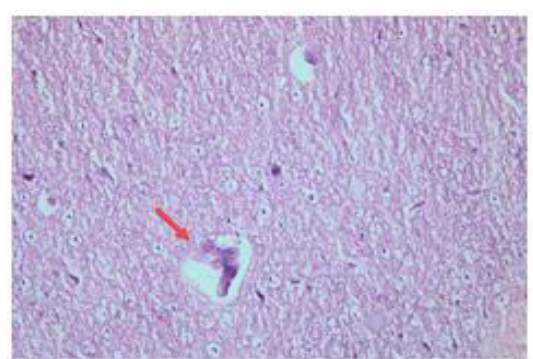

(B)

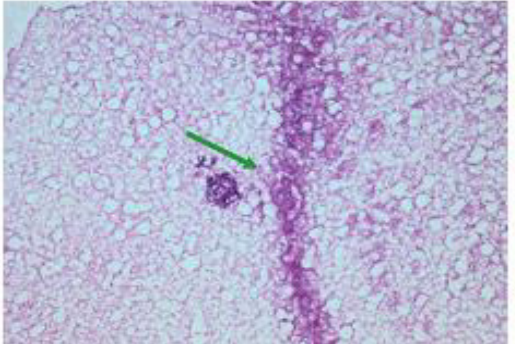

(E)

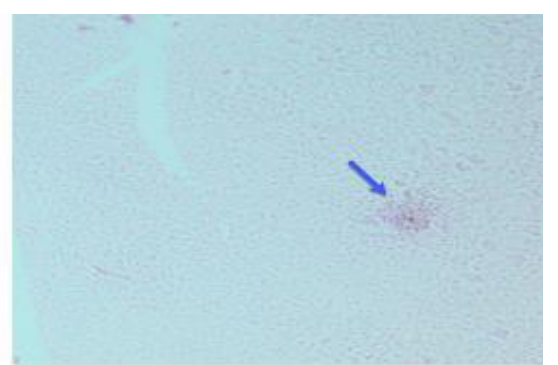

(C)

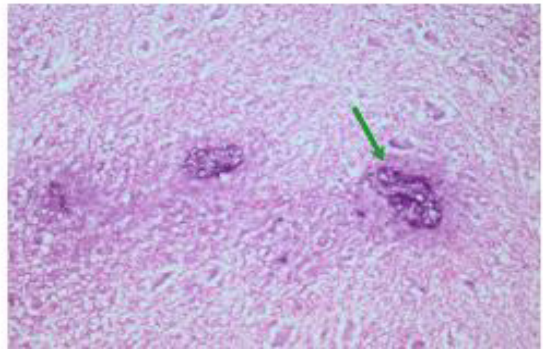

(F)

Fig. 3. Sections from brains of control and chronically-infected mice. (A) showed normal brain architecture and normal neurons (arrow) (H\&E, x200). (B) showed mature tissue cyst pathological finding (arrow). (C) showed meningitis (grade I) (arrow) (H\&E, x200). (D) showed mild lesion with mononuclear cell infiltration (grade II) (arrow) (H\&E, x200). (E) showed moderate multifocal mononuclear cell infiltration (arrow) (grade III) (H\&E, x200). (F) showed severe mononuclear cell infiltration (arrow) (grade IV) $(H \& E, x 200)$.
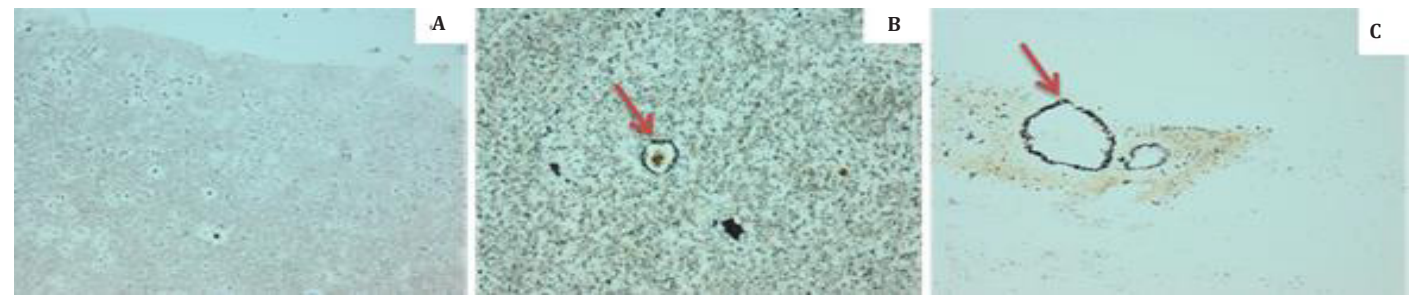

Fig. 4. Toxoplasma cysts in chronically-infected mouse brain. A: Tissue of brain of control non-infected mice (X100). B: Brain tissue of infected mice with mature cyst showing agyrophilic nature of wall (red arrow) (X200). C: Mature cyst showing wall intensely impregnated silver stain, Gordon and Sweet method (X400).

Immunohistochemical studies: The immunohistochemical assessment of CD3, CD138 and caspase-3 immunoreactivity (Figs. 5-7) showed a significant increase in CD3 expression by the activated astrocytes in the infected group indicating increased amount and function of astrocytes. Increased CD3 expression in infected groups was detected in the early phase and it progressed over time (Fig. 5 B-D). In contrast, CD3 expression was weak in the corresponding control groups (Fig. 5A). On the other hand, CD138 and caspase- 3 showed decreased expression by the activated astrocytes (Figs. 6, and 7), as compared to their strong expression in the corresponding control groups (Figs. 6A, and 7A). 


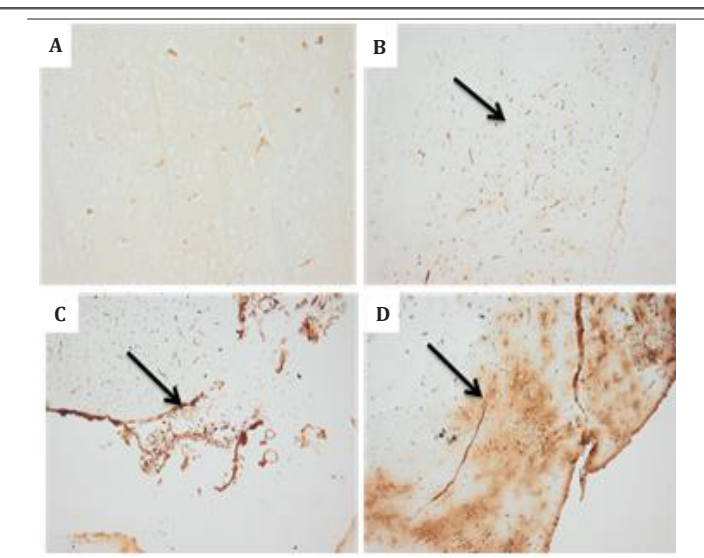

Fig. 5. Immunohistochemical staining of CD3 in brain sections. (A): Normal non-infected mice showed CD3 negative expression. (B-D): Chronically infected mice; (B): at $7^{\text {th }}$ week with CD3 increased expression; (C): at $10^{\text {th }}$ week with CD3 increased expression as compared with the highest expression in the $12^{\text {th }}$ week (D) (X200).

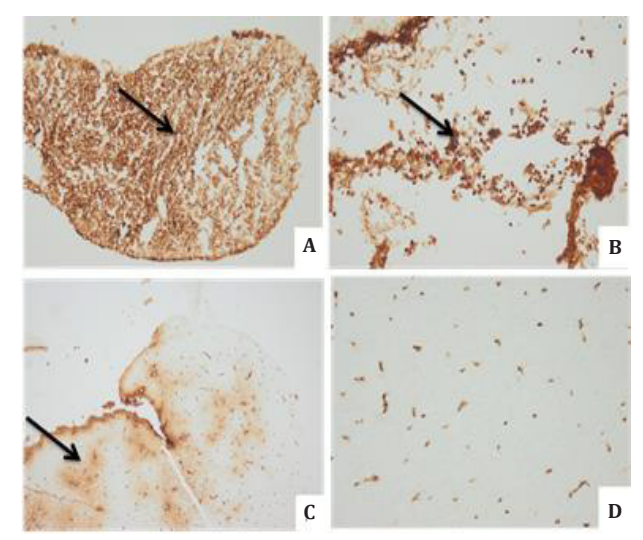

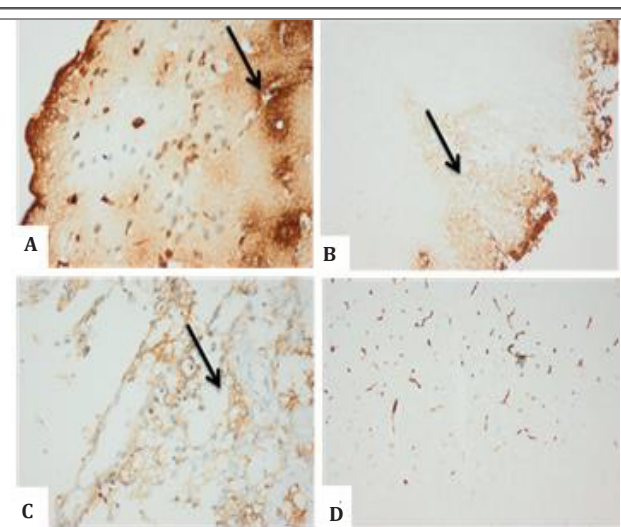

Fig. 6. Immunohistochemical staining of CD138 in brain sections. (A): Normal non-infected mice showing strong CD138 expression. (B-D): Chronically infected mice; (B): at $7^{\text {th }}$ week with reduced CD138 expression; (C) at $10^{\text {th }}$ week with marked decrease of CD138 expression as compared with the lowest expression in the $12^{\text {th }}$ week (D) (X200).

Fig. 7. Immunohistochemical staining of caspase-3 in cerebral sections (A): Normal non-infected mice showing strong caspase-3 expression. (BD): Chronically infected mice; (B): at $7^{\text {th }}$ week with decreased caspase-3 expression; (C): at $10^{\text {th }}$ week with marked decrease of caspase-3 expression as compared with the lowest expression in the $12^{\text {th }}$ week (D) (X200).

\section{DISCUSSION}

Toxoplasma gondii is an intracellular parasite that may infect any nucleated cell in any host, including humans. The formation of tissue cysts is an immune evasion mechanism that may result in brain injury ${ }^{[41]}$. Anti-toxoplasmosis drugs that work effectively combat rapidly multiplying tachyzoites that spread throughout the body and damage various tissues. Most of therapeutic agents are ineffective against brain tissue cysts due to their impaired metabolism and bloodbrain barrier resistance ${ }^{[42]}$. The predominance of a persistent infection may have a role in the development of a number of neurological and neurobehavioral problems $^{[43]}$.

Toxoplasma favors neuronal cells over resident glial cells in the CNS, where it differentiates into encysted bradyzoites and establishes a latent or chronic infection. The development of astrocytes, microglia, and neurons in toxoplasmosis was originally investigated in vitro using primary cells from murine and human fetal brains ${ }^{[44]}$. When a mixed culture of rat primary cortical cells was infected with Toxoplasma, intracellular parasites were discovered in all cell types; however, as infection progressed, astrocytes and microglia were able to successfully limit the parasites' proliferation and multiplication. After that, bradyzoite-containing vacuoles were usually discovered in neurons ${ }^{[45]}$.

Microglias derived from the monocyte/ macrophage lineage are the main immune cells or resident macrophages in the $\mathrm{CNS}^{[46]}$. The absence of a conventional lymphatic system that drains CNS antigens and the close capillary junctions of the BBB that restrict immune cell entry into the brain parenchyma, as well as astrocyte end-feet systems that connect the cells to the outside of capillary walls, have historically been known as immune privileged organs ${ }^{[47]}$. While this belief is still valid, it is now well recognized that immune cell penetration of the CNS happens not only to control pathogenic invasion but also to sustain brain homeostasis and function ${ }^{[48]}$. Neuroimmune interactions are interactions between the neurological system and the immune system that can alter cognitive function in both beneficial and negative ways ${ }^{[49]}$.

In support of our results, Hermes et al. ${ }^{[11]}$ observed that toxoplasmosis changes the appearance, behavior, 
and neurological function of mice, including autonomic function, pain sense, motor function, equilibrium, spatial awareness, grip power, balance, and loss of pain sensitivity. In our experiments, there was a significant decrease in the total distance of movements made by the infected mice compared to control mice registered by the OFT. Infected mice also spent more time in the central area than control ones. Furthermore, control groups crossed the platform position more often than affected groups in the MWM test. The affected mice spent less time in the target quadrant in the spatial probe trial than the control mice. Furthermore, in the tail suspension test, T. gondii-infected mice had a significantly longer immobility duration than control mice, indicating that infected animals had depressionlike symptoms. According to Wang etal. ${ }^{[17]}$ toxoplasmosis decreased spatial memory retention but not learning in infected mice in the MWM, which is consistent with our findings. Infected mice also displayed greater anxiety and decreased exploratory activity. We found that the extended period of immobility caused by T. gondii infection resulted in depression-like behavior in the TST test.

In our research, histopathological examination of brain sections from infected mice revealed variable degrees of perivascular and interstitial inflammatory infiltrates, astrocytosis, degenerated neurons and meningitis. Our findings showed mild parenchymal infiltrates of inflammatory cells that increased progressively over time with severe infiltration of inflammatory cells mainly lymphocytes in the $12^{\text {th }}$ week. Toxoplasma cysts were located mostly in the cortex and striatum regions of infected mouse brains, which were distant from regions of inflammation and isolated from perivascular and intra-parenchymal inflammation. Accordingly, the infected mice's brains, on the other hand, showed perivascular cuffing and lesions with vascular dilation, congestion, and lymphocytes centered around narrow blood vessels, indicating diffuse inflammation ${ }^{[17]}$.

Using immunohistochemical markers for T-lymphocytes (CD3), B-cells (CD138), and caspase-3, the current research aimed to examine the regional distribution of pathohistological indicators of neuroinflammation in the cerebral tissue of mice infected with Toxoplasma at the chronic level. Normally, these peripheral immune cells do not cross the BBB, although increased numbers of these cells were reported within brain tissue after infection ${ }^{[50]}$. As a result, an increased rate of lymphocytes in cerebral tissue outside of blood vessels may be interpreted as a sign of an active neuroinflammation phase ${ }^{[51]}$. In our infected groups, immunohistochemical analysis of CD3, CD138, and caspase- 3 revealed a substantial increase in CD3 expression by activated astrocytes clustered in the cortical parenchyma, suggesting increased astrocyte numbers and function. We found less expression of CD138 and caspase- 3 by active astrocytes in the cerebral tissue of the affected mice.

Additionally, CD3 imunoreactive cells include T-lymphocytes, T-helper cells, and cytotoxic T-cells ${ }^{[2]}$. The T-lymphocytes are also found at much greater concentrations in the peripheral blood than B-lymphocytes. Consequently, a break of the BBB could have resulted in the far higher concentrations of CD3positive cells recorded by the $7^{\text {th }}-12^{\text {th }}$ weeks in our examined brain sections. According to Murphy et al. ${ }^{[52]}$ diagnosis is made easier by using semiquantitative tissue analysis. Regarding the antibody secreting CD138C cells (plasma cells/plasmablasts), infiltration recorded in our study was increasingly reduced in the chronic phase of infection from $7^{\text {th }}-12^{\text {th }}$ week. In contrast CD138C cells may be predominant among inflammatory infiltrates in the perivascular and interstitial spaces of autopsied brain samples 3-4 weeks after symptom presentation in encephalitis patients ${ }^{[53]}$. Accordingly, it was postulated that CD138 cells can play a role in monocyte trans-endothelial migration and contribute to the development of inflammatory lesions ${ }^{[54]}$. Endothelial dysfunction in encephalitis received much interest because of its important position in BBB dysfunction, and results in encephalitis. The parasite molecules that disrupt the apoptosis signaling pathway are yet to be identified ${ }^{[55]}$.

Caspases-3 is considered a major moderator of apoptosis in neural cells. However, evidence suggests it may also have nonapoptotic functions as a regulatory molecule in neurogenesis and synaptic activity[30]. Caspases-3 activation in neural progenitors promotes neurogenesis ${ }^{[29]}$, as evidenced in our study where its expression began to drop by the $7^{\text {th }}$ week and persisted until the $12^{\text {th }}$ week indicating a nonapoptotic function.

Although some mapping research found a clear correlation between cyst concentration and the hippocampus ${ }^{[35]}$ and amygdala ${ }^{[46]}$, others did not find any relation ${ }^{[56-57]}$. Some controversy also exists with regard to the ability of specific brain cells to become infected and to house developing cysts. While there is agreement that neurons are likely to be the primary host cell of relevance ${ }^{[58,59]}$, infection of microglia and astrocytes can also play a role in the development of tissue cysts ${ }^{[11]}$.

Reports on the neurochemistry of chronic toxoplasmosis showed that the parasite causes changes in neurotransmitter levels, precursors, and metabolites $^{[43]}$. One of the possible mechanisms for modulating neuronal behavior is the injection of effector proteins by Toxoplasma' rhoptries into both parasite attacked cells as well as cells engaged without invasion $^{[60,61]}$. Accordingly, T. gondii has full control of not just the cell it infects, but also the surrounding cells ${ }^{[62]}$. 
T. gondii is also known to change the epigenome of its hosts by secreting factors that cause chromatin remodelling, transcription factor activation, and gene expression control ${ }^{[63,64]}$. Toxoplasma infected rats had greater hypomethylation at the arginine vasopressin promoters than control rats, resulting in higher medial amygdala neuron activation. As a result of this impact, infected rats were believed to lose their aversion for cat odor; and hyper-methylation was recommended as a way to help restore this characteristic ${ }^{[65]}$.

Studies also indicated that Toxoplasma infection was able to alter host micro RNA (miRNA) profiles in the brain ${ }^{[1]}$, spleen ${ }^{[66]}$, and macrophages ${ }^{[67]}$. Toxoplasma infection was known to induce a global change in the expression profiles of small non-coding RNAs in various host tissues ${ }^{[68]}$ which were believed to assist the parasite in evading the host's immune system. Tyebji et al. ${ }^{[2]}$ provided evidence that Toxoplasma infection induced epigenetic changes, involving the small non-coding RNAs, a mechanism that mediated transgenerational inheritance of some phenotypes-like behavior. The wide range of physiological and behavioral modifications show that ongoing Toxoplasma infection in the brain does cause changes, proving that these parasites are not completely inactive or latent ${ }^{[69]}$. Recent research is beginning to reveal possible mechanistic insights into the neurobiology of chronic toxoplasmosis. These results are the first significant mechanistic move into this diverse interdisciplinary area, which promises to be rich in research opportunities ${ }^{[70]}$. Although the host is aggressively fighting the parasite, there may be differences in neuronal function induced by the parasite itself, an adaptation to the inflammatory condition, and/or an influence by pro-inflammatory elements that inflict collateral damage to the neurons ${ }^{[49]}$.

In conclusion, a growing body of evidence indicates that the prevalence of a chronic infection can play a role in the pathogenesis of a variety of neurological and neurobehavioral disorders. The current hypothesis of Toxoplasma-induced behavioral changes proposes that a dynamic interplay between brain changes and immune activation contributes to an overall impairment in cognitive and affective activity in the infected host, manifesting as neuropsychiatric and behavioral disorder. The exact mechanism linking T. gondii infection and psychiatric disorders remains incompletely understood. Future research is required to clarify how $T$. gondii mediate behavioral deficits and cognitive disorders.

Acknowledgment: We would like to thank the Medical Parasitology Department, Faculty of Medicine, Alexandria University for providing the Me49 strain. Author contribution: Etewa SE conceived and designed the research idea. Sarhan MH, Moawad HSF, Samir MA, Mostafa EM were responsible for acquisition, analysis, and results interpretation. Sarhan MH, Mohammad

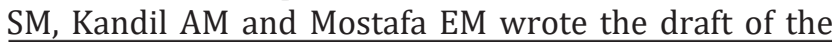

manuscript. Sarhan MH completed the critical revision of the article. Etewa SE approved the final version for publication.

Conflicts of interest: There is no conflict of interest. Financial support and sponsorship: Nil.

\section{REFERENCES}

1. Cannella D, Brenier-Pinchart MP, Braun L, van Rooyen JM, Bougdour A, Bastien 0, et al. miR-146a and miR155 delineate a MicroRNA fingerprint associated with Toxoplasma persistence in the host brain. Cell Rep 2014; 13; 6(5):928-937.

2. Tyebji S, Hannan AJ, Tonkin CJ. Pathogenic infection in male mice changes sperm small RNA profiles and transgenerationally alters offspring behavior. Cell Rep 2020; 28:31(4):107573.

3. Saad AE, Ashour DS, Dawood LM, El-Shorbagy SH. Agerelated changes in cerebral congenital toxoplasmosis: Histopathological and immunohistochemical evaluation. J Neuroimmunol 2020; 348:577384.

4. BobićB, Klun I, NikolićA, Djurković-DjakovićO.Toxoplasma gondii-infection in south-east Europe: epidemiology and epizootiology. 2012 DOI: 10.5772/50831. Available from: https://www.intechopen.com/chapters/38946.

5. Etewa SE, El-Maaty DAA, Hamza RS, Metwaly AS, Sarhan $\mathrm{MH}$, Abdel-Rahman SA, et al. Assessment of spiramycinloaded chitosan nanoparticles treatment on acute and chronic toxoplasmosis in mice. J Parasit Dis 2018; 42(1):102-113.

6. Wohlfert EA, Blader IJ, Wilson EH. Brains and brawn: Toxoplasma infections of the central nervous system and skeletal muscle. Trends Parasitol 2017; 33(7):519-531.

7. Dubey JP, Ferreira LR, Alsaad M, Verma SK, Alves DA, Holland GN, et al. Experimental toxoplasmosis in rats Induced orally with eleven strains of Toxoplasma gondii of seven genotypes: tissue tropism, tissue cyst size, neural lesions, tissue cyst rupture without reactivation, and ocular lesions PloS One 2016; 11(5):e0156255.

8. Etewa SE, Abo El-Maaty DA, El-Azeem A, El-Shafey MA, Sarhan MH, Abdel Bary EH, et al. In vivo assessment of the effects of methotrexate on latent toxoplasmosis. J Egypt Society Parasitol 2017; 47(3):589-598.

9. Sullivan Jr WJ, Smith AT, Joyce BR. Understanding mechanisms and the role of differentiation in pathogenesis of Toxoplasma gondii: a review. Mem Inst Oswaldo Cruz 2009; 104(2):155-161.

10. Tedford E, McConkey G. Neurophysiological changes induced by chronic Toxoplasma gondii infection. Pathogens 2017; 6(2):19.

11. Hermes G, Ajioka JW, Kelly KA, Mui E, Roberts F, Kasza $\mathrm{K}$, et al. Neurological and behavioral abnormalities, ventricular dilatation, altered cellular functions, inflammation, and neuronal injury in brains of mice due to common, persistent, parasitic infection. J Neuroinflam 2008; 5(1):1-37.

12. Webster JP. Rats, cats, people and parasites: the impact of latent toxoplasmosis on behavior. Microb Infect 2001; 3(12):1037-1045. 
13. da Silva RC, Langoni H. Toxoplasma gondii: host-parasite interaction and behavior manipulation. Parasitol Res 2009; 105(4):893-898.

14. Dielenberg RA, McGregor IS. Defensive behavior in rats towards predatory odors: A review. Neurosci Biobehav Rev 2001; 25(7-8):597-609.

15. Tanaka S, Nishimura M, Ihara F, Yamagishi J, Suzuki Y, Nishikawa Y. Transcriptome analysis of mouse brain infected with Toxoplasma gondii. Infect Immu 2013; 81(10):3609-3619.

16. Tyebji S, Seizova S, Hannan AJ, Tonkin CJ. Toxoplasmosis: A pathway to neuropsychiatric disorders. Neurosci Biobehav Rev 2019; 96:72-92.

17. Wang T, Sun X, Qin W, Zhang X, Wu L, Li Y, et al. From inflammatory reactions to neurotransmitter changes: implications for understanding the neurobehavioral changes in mice chronically infected with Toxoplasma gondii. Behav Brain Res 2019; 359:737-748.

18. Horacek J, Flegr J, Tintera J, Verebova K, Spaniel F, Novak T, et al. Latent toxoplasmosis reduces gray matter density in schizophrenia but not in controls: voxel-basedmorphometry (VBM) study. Wor J Biolo Psych 2012; 13(7):501-509.

19. Donley DW, Olson AR, Raisbeck MF, Fox JH, Gigley JP. Huntingtons disease mice infected with Toxoplasma gondii demonstrate early kynurenine pathway activation, altered CD8 ${ }^{+} \mathrm{T}$-cell responses, and premature mortality. PLoS One 2016; 11(9):e0162404.

20. Sutterland AL, Fond G, Kuin A, Koeter MW, Lutter R, Van Gool T, et al. Beyond the association. Toxoplasma gondii in schizophrenia, bipolar disorder, and addiction: systematic review and meta-analysis. Acta Psychiatr Scand 2015; 132(3):161-179.

21. Smith-Garvin JE, Koretzky GA, Jordan MS. T cell activation. Ann Rev Immunol 2009; 27:591-619.

22. Bogerts B, Winopal D, Schwarz S, Schlaaff K, Dobrowolny $\mathrm{H}$, Mawrin C, et al. Evidence of neuroinflammation in subgroups of schizophrenia and mood disorder patients: a semi-quantitative postmortem study of CD3 and CD20 immunoreactive lymphocytes in several brain regions. Neurol Psychitry Brain Res 2017: 23:2-9.

23. O'Connell FP, Pinkus JL, Pinkus GS. CD138 (syndecan-1), a plasma cell marker: immuno-histochemical profile in hematopoietic and nonhematopoietic neoplasms. Am J Clin Pathol 2004; 121(2):254-263.

24. Kaminski DA, Wei C, Qian Y, Rosenberg AF, Sanz I. Advances in human B cell phenotypic profiling. Front Immunol 2012; 10; 3:302.

25. DiNiro R, Mesin L, Raki M, Zheng NY, Lund-Johansen F, Lundin KE, et al. Rapid generation of rotavirus-specific human monoclonal antibodies from small- intestinal mucosa. J Immunol 2010; 185:5377-5383.

26. Oracki SA, Walker JA, Hibbs ML, Corcoran LM, Tarlinton DM. Plasma cell development and survival. Immunolo Rev 2010; 237(1):140-159.

27. Zhu J, Li X, Yin J, Hu Y, Gu Y, Pan S. Glycocalyx degradation leads to blood-brain barrier dysfunction and brain edema after asphyxia cardiac arrest in rats. J Cereb Blood Flow Meta 2018; 38(11):1979-1992.
28. Burek MJ, Oppenheim RW. Cellular interactions that regulate programmed cell death in the developing vertebrate nervous system. In: Koliatsos VE, Ratan RR ( $4^{\text {th }}$ eds) Cell death and diseases of the nervous system. Humana Press Inc, Totowa, NJ 1999: 145-179.

29. Fernando P, Brunette S, Megeney LA. Neural stem cell differentiation is dependent upon endogenous caspase 3 activity. FASEB J 2005; 19:1671-1673.

30. D'amelio M, Cavallucci V, Cecconi F. Neuronal caspase-3 signaling: not only cell death. Cell Death Differ 2010; 17(7):1104-1114.

31. Ferreira RA, de Oliveira AB, Gualberto SA, Del Corral JM, Fujiwara RT, Guimarães PH, et al. New naphthoquinones and an alkaloid with in vitro activity against Toxoplasma gondii RH and EGS strains. Exper Parasitol 2012; 132(4):450-457.

32. Elmore SA, Jones JL, Conrad PA, Patton S, Lindsay DS, Dubey JP. Toxoplasma gondii: epidemiology, feline clinical aspects, and prevention. Trends Parasitol 2010; 26(4):190-196.

33. Turner PV, Pang DS, Lofgren JL. A review of pain assessment methods in laboratory rodents. Comp Med 2019; 69(6):451-467.

34. Vidal S, Gros P, Skamene E: Natural resistance to infection with intracellular parasites: molecular genetics identifies Nramp1 as the Bcg/Ity/Lsh locus. J Leukoc Biol 1995, 58:382-390.

35. Gatkowska J, Wieczorek M, Dziadek B, Dzitko K, Dlugonska H. Behavioral changes in mice caused by Toxoplasma gondii invasion of brain. Parasitol Res 2012; 111(1):53-58.

36. Elsheikha HM, Büsselberg D, Zhu XQ. The known and missing links between Toxoplasma gondii and schizophrenia. Metab Brain Dis 2016; 31(4):749-759.

37. Kaňková Š, Holáň V, Zajícová A, Kodym P, Flegr J. Modulation of immunity in mice with latent toxoplasmosis: The experimental support for the immunosuppression hypothesis of Toxoplasmainduced changes in reproduction of mice and humans. Parasitol Res 2010; 107(6):1421-1427.

38. Bancroft JD, Gamble M (Editors). Theory and practice of histological techniques. $6^{\text {th }}$ edition; Churchill Livingstone Elsevier Health Sciences China; 2008:121433.

39. Attwood HD, Woolley PA, Rickard MD. Toxoplasmosis in dasyurid marsupials. J Wildlife Dis 1975; 11(4):543551.

40. Busse S, Busse M, Schiltz K, Bielau H, Gos T, Brisch R, et al. Different distribution patterns of lymphocytes and microglia in the hippocampus of patients with residual versus paranoid schizophrenia: further evidence for disease course-related immune alterations? Brain Behav Immu 2012; 26(8):1273-1279.

41. Etewa SE, Al-Hoot AA, Abdelmoaty SM, Mohammad SM, Moawad HS, Sarhan MH, et al. The outcomes of mesenchymal stem cells therapy for experimental toxoplasmosis. PUJ 2019; 12(1):34-44.

42. Schultz TL, Hencken CP, Woodard LE, Posner GH, Yolken RH, Jones-Brando L, et al. A thiazole derivative of 
artemisinin moderately reduces Toxoplasma gondii cyst burden in infected mice. J Parasitol 2014; 100:516-521.

43. Sinai AP, Watts EA, Dhara A, Murphy RD, Gentry MS, Patwardhan A. Reexamining chronic Toxoplasma gondii infection: surprising activity for a "dormant" parasite. Curr Clin Microbiol Rep 2016; 3(4):175-185.

44. Contreras-Ochoa CO, Lagunas-Martínez A, Belkind-Gerson J, Díaz-Chávez J, Correa D. Toxoplasma gondii invasion and replication within neonate mouse astrocytes and changes in apoptosis related molecules. Exper Parasitol 2013; 134(2):256-265.

45. Lüder CG, Giraldo-Velásquez M, Sendtner M, Gross U. Toxoplasma gondii in primary rat CNS cells: Differential contribution of neurons, astrocytes, and microglial cells for the intracerebral development and stage differentiation. Exp Parasitol 1999; 93(1):23-32.

46. Vyas A. Mechanisms of host behavioral change in Toxoplasma gondii rodent association. PLoS Pathog 2015; 11(7):e1004935.

47. Carson Monica J, Doose Jonathan M, Melchior Benoit, Schmid Christoph D, Ploix Corinne C. CNS immune privilege: hiding in plain sight. Immunolog Rev 2006; 213:48-65.

48. Louveau A, Harris TH, Kipnis J. Revisiting the mechanisms of CNS immune privilege. Trends Immunol 2015; 36(10):569-577.

49. Tyebji S, Seizova S, Garnham AL, Hannan AJ, Tonkin CJ. Impaired social behaviour and molecular mediators of associated neural circuits during chronic Toxoplasma gondii infection in female mice. Brain Behav Immun 2019; 80:88-108.

50. Barcia C, Gomez A, de Pablos V, Fernández-Villalba E, Liu C, Kroeger KM, et al. CD20, CD3, and CD40 ligand microclusters segregate three-dimensionally in vivo at B-cell-T-cell immunological synapses after viral immunity in primate brain. J Vir 2008 15; 82(20):9978-9993.

51. Wohleb ES, Godbout JP. Basic aspects of the immunology of neuroinflammation. Mod Trends Pharmacopsychiatry 2013; 28:1-9.

52. Murphy K, Travers P, Walport M, Janeway C. Janeway's immunobiology. $8^{\text {th }}$ edition, 2012; Garland Science, New York.

53. Martinez-Hernandez E, Horvath J, Shiloh-Malawsky Y, Sangha N, Martinez-Lage M, Dalmau J. Analysis of complement and plasma cells in the brain of patients with anti-NMDAR encephalitis. Neurology 2011; 77(6):589593.

54. Zhang X, Wu C, Song J, Götte M, Sorokin L. Syndecan-1, a cell surface proteoglycan, negatively regulates initial leukocyte recruitment to the brain across the choroid plexus in murine experimental autoimmune encephalomyelitis. J Immunol 2013; 191(9):4551-4561.

55. Maubon D, Ajzenberg D, Brenier-Pinchart MP, Dardé ML, Pelloux H. What are the respective host and parasite contributions to toxoplasmosis? Trends Parasitol 2008; 24(7):299-303.

56. Di Cristina M, Marocco D, Galizi R, Proietti C, Spaccapelo $\mathrm{R}$, Crisanti A. Temporal and spatial distribution of
Toxoplasma gondii differentiation into bradyzoites and tissue cyst formation in vivo. Infect Immun 2008; 76(8):3491-501.

57. Berenreiterová $M$, Flegr J, Kuběna AA, Němec P. The distribution of Toxoplasma gondii cysts in the brain of a mouse with latent toxoplasmosis: Implications for the behavioral manipulation hypothesis. PloS one 2011; 6(12):e28925.

58. Dubey JP, Ferreira LR, Alsaad M, Verma SK, Alves DA, Holland GN, et al. Experimental toxoplasmosis in rats induced orally with eleven strains of Toxoplasma gondii of seven genotypes: tissue tropism, tissue cyst size, neural lesions, tissue cyst rupture without reactivation, and ocular lesions. PLoS One 2016; 11:e0156255.

59. Cabral CM, Tuladhar S, Dietrich HK, Nguyen E, MacDonald WR, Trivedi T, et al. Neurons are the primary target cell for the brain- tropic intracellular parasite Toxoplasma gondii. PLoS Pathog 2016; 12(2):e1005447.

60. Melzer TC, Cranston HJ, Weiss LM, Halonen SK. Host cell preference of Toxoplasma gondii cysts in murine brain: A confocal study. J Neuroparasitol 2010; 1:N100505.

61. Koshy AA, Dietrich HK, Christian DA, Melehani JH, Shastri AJ, Hunter CA, et al. Toxoplasma co-opts host cells it does not invade. PLoS Pathog 2012; 8(7):e1002825.

62. Boothroyd JC, Dubremetz JF. Kiss and spit: The dual roles of Toxoplasma rhoptries. Nat Rev Microbiol 2008; 6(1):79-88.

63. Sibley LD, QiuW, Fentress S, Taylor SJ, Khan A, Hui R. Forward genetics in Toxoplasma gondii reveals a family of rhoptry kinases that mediates pathogenesis. Eukaryot Cell 2009; 8(8):1085-1093.

64. Cheeseman K, Weitzman JB. Host-parasite interactions: an intimate epigenetic relationship. Cell Microbiol 2015; 17(8):1121-1132.

65. Hari Dass SA, Vyas A. Toxoplasma gondii infection reduces predator aversion in rats through epigenetic modulation in the host medial amygdala. Mol Ecol 2014; 23(24):61146122.

66. He JJ, Ma J, Wang JL, Xu MJ, Zhu XQ. Analysis of miRNA expression profiling in mouse spleen affected by acute Toxoplasma gondii infection. Infection. Genet Evol 2016; 37: 137-142.

67. Li S, Yang J, Wang L, Du F, Zhao J, Fang R. Expression profile of microRNAs in porcine alveolar macrophages after Toxoplasma gondii infection. Parasit Vect 2019; 12(1):1-11

68. Menard KL, Haskins BE, Denkers EY. Impact of Toxoplasma gondii infection on host non-coding RNA responses. Front Cell Infect Microbiol 2019; 9:132.

69. Ingram WM, Goodrich LM, Robey EA, Eisen MB. Mice infected with low-virulence strains of Toxoplasma gondii lose their innate aversion to cat urine, even after extensive parasite clearance. PloS one 2013; 8(9):e75246.

70. Hakimi MA, Olias P, Sibley LD. Toxoplasma effectors targeting host signaling and transcription. Clin Microbiol Rev 2017; 30(3):615-645. 